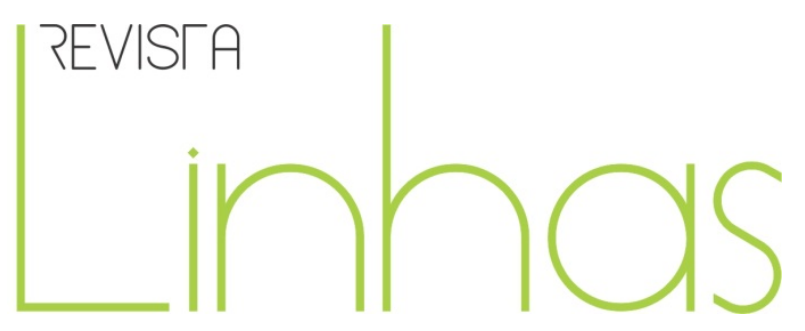

\title{
Resenha do livro Abrindo o Baú de Memórias: Políticas Culturais no Brasil - subsídios para construção de brasilidade - (1930-1990)
}

CURY, Cláudia Engler. Abrindo o Baú de Memórias: Políticas Culturais no Brasil - subsídios para construção de brasilidade - (1930-1990). João Pessoa: Editora da UFPB, 2013.

\author{
Márcia Regina dos Santos \\ Mestranda em Educação pela \\ Universidade do Estado de Santa Catarina - UDESC - Brasil \\ marcia0705@gmail.com
}

\section{Para citar esta resenha:}

SANTOS, Márcia Regina dos. Resenha do livro Abrindo o Baú de Memórias: Políticas Culturais no Brasil subsídios para construção de brasilidade - (1930-1990). Revista Linhas. Florianópolis, v. 16, n. 30, p. 301 - 306 , jan./abr. 2015.

DOI: $10.5965 / 1984723816302015301$

http://dx.doi.org/10.5965/1984723816302015301 
As relações que foram construídas entre memória e história estão muito distantes de serem amistosas. É um campo configurado entre tensões, disputas e negociações que fazem emergir uma incrível pluralidade de perspectivas sobre o passado. O presente livro, fruto da tese de doutoramento da professora e pesquisadora Cláudia Engler Cury, pela Universidade Estadual de Campinas (UNICAMP), em 2002, constitui-se num privilegiado momento de discussão sobre as políticas culturais que transversalizaram a construção do que se chama de patrimônio cultural, valendo-se dos subsídios fornecidos pela memória e pela história. O objeto de análise escolhido pela autora, os museus de rua ${ }^{1}$ de São Paulo, viabilizam diversas frentes de discussão como a institucionalização da memória, os lugares delimitados para esta e todas as elaborações coletivas que são estimuladas pelo tratamento deste objeto cultural. Ao abrir este Baú de Memórias, Cláudia Engler Cury dá vasão a estas discussões e aprofunda um aspecto intimamente ligado a todo este processo: a construção da brasilidade.

O primeiro capítulo, intitulado Políticas culturais e projetos de brasilidade em períodos ditatoriais, expõe um panorama da atuação do Estado a partir de 1930 em relação ao projeto legitimador da construção de uma identidade e uma memória nacional. O governo de Getúlio Vargas foi percebido como ponto de referência da concentração de esforços em torno da invenção de um patrimônio histórico do país. Apesar da mobilização intelectual em torno do assunto ser anterior a 1930, a criação do Serviço do Patrimônio Histórico e Artístico Nacional (SPHAN)², em 1937, é sinalizada como importante marco da apropriação por parte do Estado das questões relativas à cultura. Esse período vai ser rico em ações que pretendiam delinear quais seriam as bases culturais consideradas nacionalmente. Essas ações foram desde a elaboração de critérios de definição sobre o que era ou não era considerado patrimonializável ${ }^{3}$, instituição de campanhas midiáticas ${ }^{4}$ a

\footnotetext{
${ }^{1}$ Modelos de materialização da memória urbana implementados pelo poder público em São Paulo em lugares de grande circulação para promover certa identidade coletiva.

2 Concordando com movimentos internacionais de preservação cultural, esse órgão foi regulamentado através do Decreto-lei $n^{\circ} 25$ de 30 de novembro de 1937, que versa sobre a organização da proteção do Patrimônio Histórico e Artístico Nacional. Criado para funcionar como sistematizador das políticas culturais, direcionando a organização de bens materiais (edificações ou acervos) que poderiam configurar patrimônios culturais do país, criando o que ficou conhecido como cultura da pedra e cal. Foi considerado um importante marco por autores como Maria Cecília Londres Fonseca e José Reginaldo Santos Gonçalves.

${ }^{3}$ Nesse sentido, atribuía-se valor e importância a obras de arte, artefatos antigos, prédios e construções com base na antiguidade, raridade ou procedência, para definir o que poderia ser considerado patrimônio
} 
respeito da divulgação dos valores primordiais da identidade da nação, até a negação das questões regionalistas que eram, inclusive, legitimadas em alguma instância por projetos homogeneizantes veiculados através dos sistemas escolares.

Com o desejo incessante de fundar uma autêntica cultura brasileira, inúmeros discursos foram incorporados de modo a dar forma ao padrão que se julgava ideal. A elite intelectual do país dos anos 1930 constituiu um importante grupo que participou desse processo. Obras de escritores como Gilberto Freyre e Sérgio Buarque de Holanda, passaram a subsidiar teses que buscavam positivar a imagem de um povo mestiço e diverso que era supostamente incluído pelas premissas da ordem e do progresso. A autora discute que, apesar de estar evidenciado o caráter múltiplo da sociedade brasileira, a invenção da brasilidade transformava-se em ação política com pretensões de uniformidade. Todo um aparato de monumentos, comemorações, lugares de memória, simbologias foi construído para dar forma a essa homogeneidade cultural que se pretendia instituir.

Na década de 1960, poucas mudanças foram observadas, destacando a relevância dos movimentos em torno da democratização do acesso à cultura com maior destaque para os Centros Populares de Cultura (CPC) e o trabalho da União Nacional de Estudantes (UNE). Já na década de 1970, com a análise dos Planos Nacionais de Cultura de 1973 e $1975^{5}$, foi possível identificar novas movimentações em torno das discussões a respeito das políticas culturais, com medidas importantes e criações de órgãos. Neste sentido, é importante destacar a criação do Centro Nacional de Referência Cultural (CNRC), em 1975, que ampliou a visão sobre a cultura brasileira, agregando a observância sobre bens imateriais como práticas, costumes, memórias, enfim, as chamadas manifestações populares.

\footnotetext{
histórico.

${ }^{4}$ Essa questão incluía uma produção jornalística e cinematográfica exaltando valores simbólicos de caráter cívico e patriótico que projetavam a perspectiva de unicidade frente a pátria, colocando todas as culturas dissonantes sob a mesma égide.

${ }^{5}$ Documentos que possibilitaram à autora perceber a "tutela" do Estado sobre as questões culturais que evidenciaram "ações pedagógicas não-formais" para a configuração da memória, da identidade e na forja da brasilidade.
} 
No segundo capítulo foi remontada a cena político-social dos anos 1980 no Brasil, observando a questão da redemocratização e as perspectivas que circulavam sobre a memória e a identidade nacional. No momento histórico em que emergiram movimentos que buscavam construir uma nova cidadania que contemplasse a diversidade cultural que constitui o país, foi criado, em 1985, o Ministério da Cultura (Minc), desvinculando as políticas culturais do Ministério da Educação e Cultura, lugar onde até então eram elaborados os projetos e desenvolvidas as ações relativas à produção cultural. O texto da Constituição de 1988, em seus artigos 215 e 216, fez referência ao acesso à cultura para todos os grupos sociais, ao reconhecimento do caráter múltiplo da cultura nacional e ao alargamento do conceito de patrimônio, considerando em igual relevância os bens materiais e imateriais. Isso vai ser confirmado no ano de 2000, com o Decreto-lei $\mathrm{n}^{\circ} 3.551$ que incluiu os bens de natureza imaterial como culturais e criou o Programa Nacional do Patrimônio Imaterial ${ }^{6}$. No que tange as políticas culturais, a década de 1980 foi tempo de organizar, repensar e remodelar os projetos e as ações, até mesmo por que esse movimento acompanhou a transição para a redemocratização.

O capítulo que Cláudia Egler Cury nomeia de Políticas culturais no território da cidade, inicia com uma discussão sobre os territórios ${ }^{7}$ da cidade, no caso São Paulo, sua ocupação, sua apropriação e as negociações existentes entre os habitantes, os espaços, as memórias e a constituição de uma identificação com o local. A percepção sobre as relações que definem uma cidade e as subjetividades que envolvem esse processo foram fundamentais para pensar a formação da memória individual e coletiva dos que ocupam o território. Quando estas subjetividades passam pela apropriação institucional que se vale das mesmas para empreender projetos e até mesmo para escrever a história, segundo a autora, acabam ocorrendo ações contundentes e homogeneizantes que atropelam a relevância do peculiar em favor da obtenção de uma identidade uniforme, que atenda as

\footnotetext{
${ }^{6}$ Este programa vai sistematizar o reconhecimento dos bens culturais imateriais através da constituição de quatro Livros de Registro para inventariar e desenvolver políticas de preservação. São eles: Livro dos Saberes, Livro das Celebrações, Livro das Formas de Expressão e Livro dos Lugares, e o Decreto-lei ainda abre a possibilidade de criação de outros livros.

${ }^{7}$ A autora explica sua preferência pelo termo "território" e não "espaço", aproximando sua perspectiva do trabalho de Raquel Rolnik (1992), que compreende que "não existe um território sem um sujeito, e pode existir um espaço independente do sujeito. $O$ espaço do mapa dos urbanistas é um espaço; o espaço real vivido é o território".
} 
demandas maiores como a urbanização e a modernização. A cidade, vista como um espaço de disputa identitária, atua como disciplinadora das formas de habitar e de viver.

E é sob essa ótica conflituosa que vão emergir os Museus de Rua analisados nesta obra. Eles vão circular em São Paulo na década de 1970 e depois vão ser retomados nas décadas de 1980 e 1990, e a autora dirige-se aos dois momentos como primeira e segunda versão, respectivamente. Na primeira versão, esses elementos culturais foram pensados como a constituição de uma memória coletiva. Com ações organizadas pelo poder público, através da atuação da Secretaria Municipal da Cultura, foram ocupados espaços públicos de intensa circulação de pessoas, com a exposição de imagens da cidade em épocas passadas, com a ideia de suscitar reflexões sobre as mudanças, as permanências e as perspectivas daquele espaço comum, componente das memórias individuais.

Nesta primeira versão, foi organizado um acervo iconográfico que compôs três exposições que tratavam sobre: Percurso Centro Histórico, História do Anhangabaú e do Viaduto do Chá e Memória da Sé. As imagens eram reproduções fotográficas expostas em painéis acompanhadas de legendas e documentos escritos com informações complementares à leitura daquelas imagens que já falavam por si. Não constava nenhum tipo de análise ou problematização, os documentos apenas estavam disponíveis furtando ao leitor/transeunte como ia estabelecer esse contato.

Na segunda versão dos Museus de Rua, a dinâmica diferenciou-se muito. A começar pelo acolhimento institucional que veio por parte da Secretaria Estadual da Cultura, e também a iniciativa que partiu do que a autora percebeu nos documentos como um militante da cultura. Trata-se de um antigo morador do Bairro Cambuci, que se empenhou na elaboração e execução de um projeto que pretendia constituir uma memória coletiva a partir dos próprios moradores. Esse trabalho foi articulado através da arrecadação de imagens que estavam esquecidas em acervos pessoais, entrevistas com moradores e a interação com escolas.

Nas duas versões dos Museus de Rua foi possível identificar metodologias de criação de lugares de memória, estratégias de articulação da memória urbana e possibilidades de apropriação por parte dos sujeitos envolvidos. Se na primeira versão, a 
sensibilização passou pela afetividade das lembranças, na segunda, afirmou um elo entre os habitantes, sua história e a história do lugar. As iniciativas de construção de memória podem utilizar vários meios que de toda maneira não significam que vão reverberar da forma esperada.

Por fim, a autora pondera que as políticas culturais preservacionistas, principalmente com relação ao patrimônio, foram evidenciadas em momentos históricos - Estado Novo e regime militar, em que o exercício da cidadania era limitado e havia a necessidade de afirmação da brasilidade. Mesmo as ações estando inseridas numa ordem mercadológica de consumo, percorreram a direção de sistematizar o direito à cultura como direito de cidadão, elemento fundamental na construção da memória coletiva que é conveniente afirmar e na identidade que se pretende forjar para constituir uma cultura nacional.

Recebido em: 14/10/2014 Aprovado em: 12/11/2014

Universidade do Estado de Santa Catarina - UDESC Programa de Pós-Graduação em Educação - PPGE Revista Linhas Volume 16 - Número 30 - Ano 2015 revistalinhas@gmail.com 